\title{
THE EFFECT OF FRUCTOSE INGESTION ON BLOOD FRUCTOSE IN PSYCHOTIC PATIENTS
}

\author{
BY \\ W. M. F. ROBERTSON and T. M. WILSON \\ From the West of Scotland Psychiatric Research Institute and the Gartloch Mental \\ Hospital, Gartcosh, Glasgow
}

(Received 15Th February, 1939)

LIVER function tests have so far been of very limited value in nervous and mental disorders, because they only detect gross hepatic damage and do not assess early functional change. The blood sugar curves of mental patients and epileptics who had taken $50 \mathrm{gm}$. fructose by mouth have been studied by Mann (1925) and Guirdham (1936) with inconclusive results. Hoskins and Sleeper (1933) measured the galactose tolerance and bromsulphthalein excretion, and found a variable and inconsistent degree of liver inefficiency. The detoxication of benzoic acid by its conversion to hippuric acid has been studied in schizophrenics by Quastel and Wales (1938), whose results suggested a diminished capacity of catatonic patients to excrete hippuric acid, but these await confirmation.

In recent years two methods have been developed for the estimation of fructose which are applicable to clinical work. Van Creveld (1927) introduced a colorimetric method, utilizing the blue colour produced on heating fructose with di-phenylamine in acid solution. This technique has been used by Radt (1928) and Corley (1929) and was later modified by Patterson (1935). The second method, developed by Scott (1935a), makes use of the purple-red colour produced when fructose is heated with bile salts and hydrochloric acid, this reaction being an adaptation of the well-known Pettenkoffer test. The latter method has been used for fructose tolerance test in an unselected group of psychotic patients whose illness was well established. Among the 50 cases examined only two had clinically defined liver disease. The series is sufficiently large to allow the resulting curves to be arranged into four groups, illustrated by charts.

The Van-den-Bergh reaction and Icteric Index were also measured and Scott's (1933) method of stool urobilinogen estimation was employed. Our findings are very largely negative, and are thus in keeping with those of former workers. 


\section{Method}

Fifty gm. of pure fructose were given in 300 c.c. of water after a night's fast of not less than 16 hours. No patient vomited (cf. Stewart et al., 1937). Fructose was estimated by a slight modification of Scott's (1935a) method. Five c.c. of blood, taken from an arm vein with slight stasis, were discharged directly into 25 c.c. of distilled water. Deproteinization with 5 c.c. of 10 -per cent. zinc sulphate and 5 c.c. $0.5 \mathrm{~N}$-sodium hydroxide followed after not more than 5 minutes' allowance for laking. The com-

\section{Chart 1.-Group 1. Curves (Twelve) Psychotic Subjects}

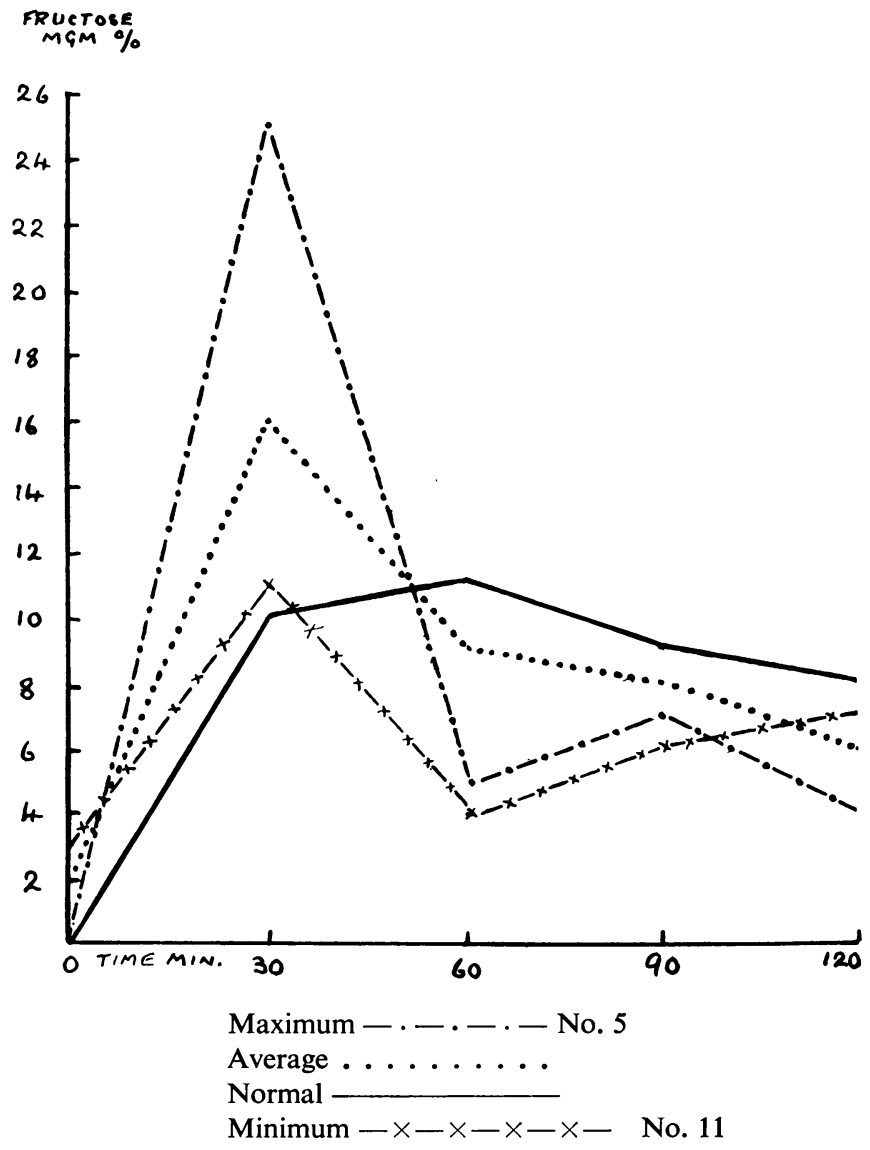

mercial bile salt used by Scott gave a brown colour in blank estimations (and in the presence of fructose), which interfered considerably with the estimation of the purplered colour produced by small amounts of fructose. We have reduced the quantity of bile substance recommended by Scott to one half and have substituted glycocholic acid prepared from ox bile for the commercial bile salts. This reduced the brown coloration, but did not affect to any extent the purple-red coloration due to fructose. Parallel determinations on duplicate filtrates, undertaken by us and by Dr. Scott at the beginning of this work, gave results substantially in agreement. The method as 
modified is considered to give values correct to about $4 \mathrm{mgm}$. per 100 c.c. This statement is made in the light of further modification and tests of the method, which will be reported in future publications. The results given in our table must, of course, be interpreted with this estimate of their accuracy in mind.

To obtain some idea of the measure of agreement between Patterson's and Scott's methods, the fructose in 24 specimens of blood was estimated by both methods in the course of six tolerance tests. The two methods showed an average difference of $\pm 2.7 \mathrm{mgm}$. per 100 c.c., the findings by Patterson's method being on the average

Chart 2.-Group 2. Curves (Sixteen) Psychotic Subjects

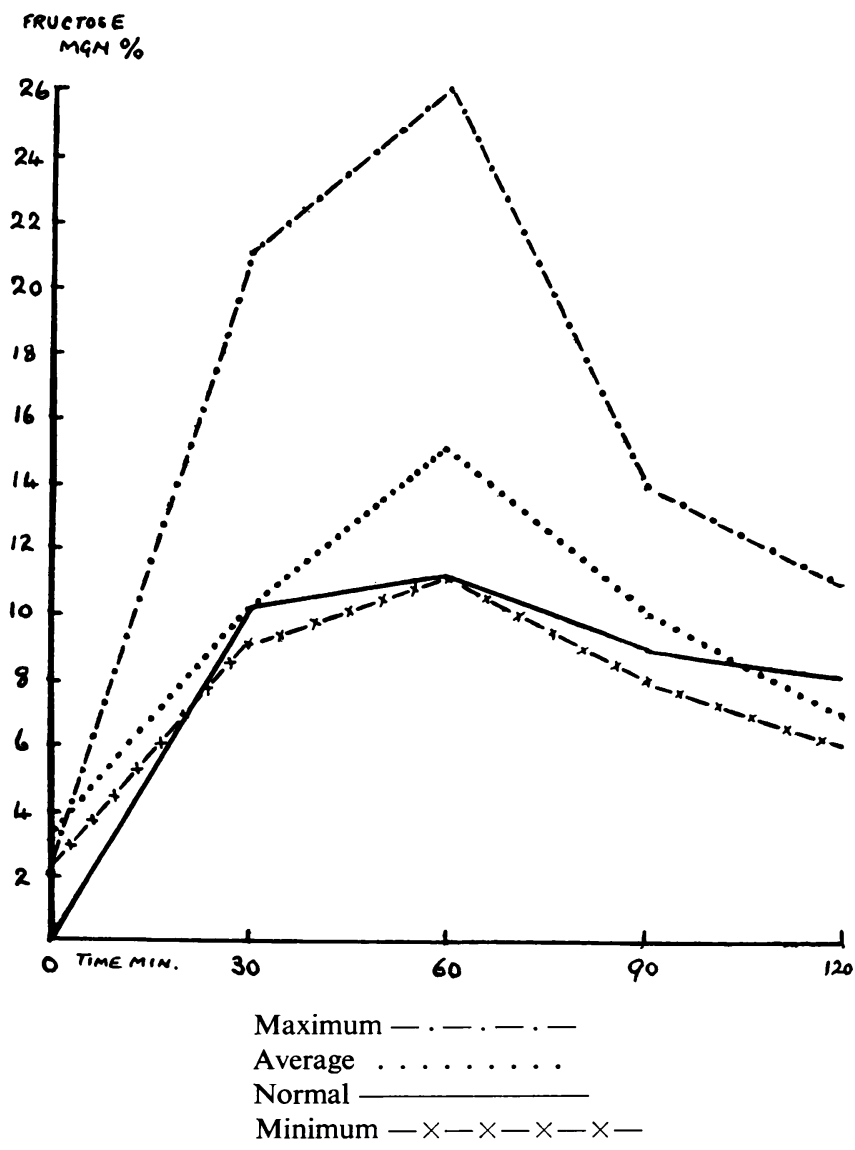

$1.5 \mathrm{mgm}$. per 100 c.c. higher. A fair approximation between the two is thereby shown. Probably the Patterson method gives errors of the same order as the modified Scott method. Patterson's method has been employed by Herbert (1938a) and by Stewart et al. (1937) in fructose tolerance tests. The average values given for normal control groups by Stewart et al. (1937) and Herbert (1938b) at the 1-hour test period are similar, viz. $12.6 \mathrm{mgm}$. per 100 c.c. on eight cases and $11.9 \mathrm{mgm}$. per 100 c.c. on thirteen cases respectively. Herbert stated that the upper limit for normal and pathological subjects without hepatic disease should be $15 \mathrm{mgm}$. per 100 c.c. 1 hour after administering the fructose. Stewart et al. based their normal range on the half-hour figures and 
placed the upper limit at $20 \mathrm{mgm}$. per 100 c.c. Scott's $(1935 \mathrm{~b})$ control series of six normals gave lower values, $10 \mathrm{mgm}$. per 100 c.c. at 1 hour and $8 \mathrm{mgm}$. per 100 c.c. at the end of 2 hours, and figures above these were regarded as outside the normal range. We have compared Scott's findings for normal subjects with those of our psychotic patients. The inclusion of the "normal" curve in the charts can only be regarded as an approximation to the probable normal, but nevertheless this device serves to show up the wide variations in the response of our patients. The fasting levels have been included, which in our series averaged $2.6 \mathrm{mgm}$. per 100 c.c. Herbert's average for patients without liver disease was

Chart 3.-Group 3. Curves (Ten) Psychotic Subjects

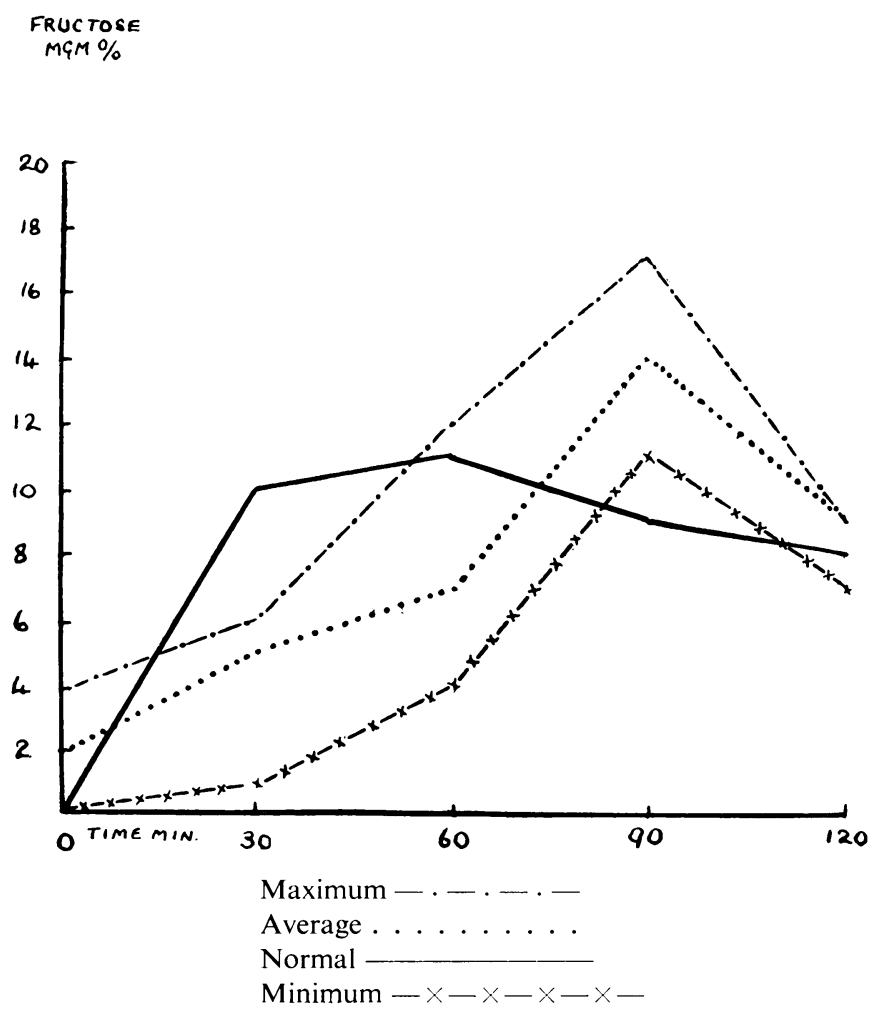

$8.6 \mathrm{mgm}$. per 100 c.c., and with an improved method Herbert (1938a) has now obtained much lower values in normal subjects. Since a limit of accuracy of some $4 \mathrm{mgm}$. per 100 c.c. has to be taken into account, we consider it unsafe to assume that values below $5 \mathrm{mgm}$. per 100 c.c. are as accurate as those obtained after administration of fructose. We have not deducted our fasting figures from those obtained after fructose administration. 


\section{Results}

The curves, illustrated by four charts, are divided into four groups, the first with peaks at 30 minutes, the second at 60 minutes, the third at 90 minutes, and the fourth being mixed curves with no points above $11 \mathrm{mgm}$. per 100 c.c. On each chart is shown the maximum, minimum, and average fructose levels and Scott's upper limit for his control series.

Chart 1 is made up from twelve curves with peaks at half an hour, the values ranging from 11 to $25 \mathrm{mgm}$. per 100 c.c., the average being $16 \mathrm{mgm}$. per 100 c.c. The fall at the 1-hour stage was considerable in about half the cases. The difference from Scott's normal level for the corresponding

Chart 4.-Group 4. Curves (Twelve) Psychotic Subjects

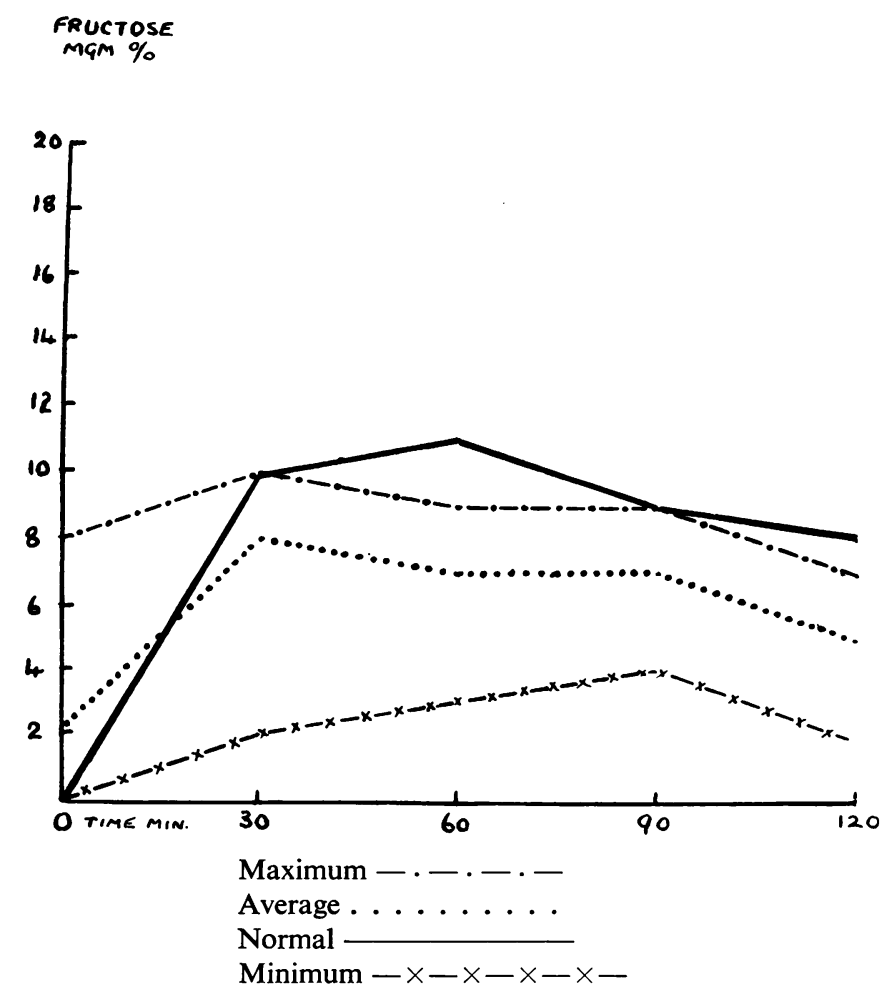

period was well shown, but only one curve rose above Stewart's upper limit of normality.

Chart 2 is derived from 16 cases with peak values at 1 hour, ranging from 11 to $26 \mathrm{mgm}$. per 100 c.c., with an average figure of $15 \mathrm{mgm}$. per 100 c.c. Five of these curves lay above Herbert's upper limit for subjects without liver disease, whereas all but one failed to conform to that of Scott. The 
three highest points were 26,19 , and $17 \mathrm{mgm}$. per 100 c.c. The first two of these were diabetics and the last had persistent jaundice.

Chart 3 is made up from ten curves with a peak at one and a half hours, and of these two reached a level of $17 \mathrm{mgm}$. per 100 c.c. In Stewart's control series the maximum value at one and a half hours was $12.5 \mathrm{mgm}$. per 100 c.c. and five of this series were above this figure.

Chart 4 comprises the curves which had no point above $11 \mathrm{mgm}$. per 100 c.c. : three of which did not rise above $6 \mathrm{mgm}$. per 100 c.c. ; one did not exceed $4 \mathrm{mgm}$. per 100 c.c. It is to be noted that one of the lowest in this group had frank liver disease. The series as a whole represented a wide variation of fructose utilization and probably of absorption.

\section{Discussion}

With the acceptance of the reservation already placed on the interpretation of the findings, a comparison with Stewart's normal results indicates that there were only eight abnormal curves in the present series. Of these, four had nonhepatic organic diseases, one had a disorder of the liver, while three were in good health. On the other hand, if Herbert's $15 \mathrm{mgm}$. per 100 c.c. is taken as the upper limit of normal, about a third of the curves can be regarded as abnormal. The interpretation of such curves in relation to the psychoses is admittedly speculative. The difficulty is emphasized by their examination on the basis of the physical health of the patient. Variability in the rate of absorption of fructose has also to be taken into account in the interpretation of some of the anomalous results.

Analysis of 16 abnormal curves of $15 \mathrm{mgm}$. per 100 c.c. and higher into their curve grouping, if compared with those below this level, gave the following results.

In Group 1 (30 min. curve-apex type) all of six cases were physically healthy, being well-nourished and free from organic conditions. The clinical grouping seems to be beyond coincidence, and absorption in excess of fructose utilization has to be regarded as likely to be a dominant factor in transient fructosemia.

In Group 2 (60 min. curve-apex type), by contrast, none of the seven could be classified as being in good health, such conditions as diabetes, cerebral syphilis, arterio-sclerosis, obstructive jaundice, and marked asthenia being present. At least some relation between the above organic diseases and the abnormal curves seems to exist.

Some of the thirty-four normal curves may have been due to a partial failure to absorb the fructose, particularly in six with peaks less than $10 \mathrm{mgm}$. per 100 c.c. All but two of these were in poor health; one had obstructive jaundice due to gall stones.

The most reliable time at which to assess the normality of a curve therefore 
would appear to be at 1 hour. This is in agreement with Herbert's (1938b) findings, though somewhat contrary to those of Stewart (1937), who places reliance on 30-minute figures. Scott $(1935 b)$, on the other hand, regards high 2-hour values as probably more significant.

The nine cases of schizophrenia, uncomplicated by organic disease, are the only psychotic group on whom fructose curves can be examined. Six exhibited some of the lowest responses. Failure of absorption rather than high fructose tolerance appears to be the likely explanation. The remaining three showed diminished tolerance ; two, however, belonged to the 30-minutes peak type. These, as already shown, are not likely to be true liver deficiencies. Only one could therefore be suspected of having liver disorder.

The other mental states in the series are either too limited in number or too variable in response to permit delineation. From these observations it is clear that evaluation of hepatic function in mental disorders is difficult, and it seems permissible to emphasize that care must be taken in the selection of the clinical material, that all patients giving abnormal curves, high or low should be tested a second time, and that the rate of fructose absorption probably influences results.

\section{Summary}

Scott's bile salts method, slightly modified, has been used to determine the fructose tolerance in 50 established psychotic patients, unselected as regards mental or physical state.

The findings indicate a wide range of fructose tolerance, and while curves have been obtained which are outside the accepted normal range, their interpretation and relationship to the psychoses is most uncertain.

It is probable that rate of absorption plays a large part in determining the form of the curves, particularly in schizophrenia.

We wish to acknowledge Dr. Scott's advice and assistance in the earlier stages of this research. Our thanks are also due to Dr. A. M. Dryden, Medical Superintendent of Gartloch Mental Hospital, for granting access to clinical material, and to Mr. A. P. Kenny, Biochemical Assistant, for his preparation of glycocholic acid from ox bile and for much of the technical work.

\section{REFERENCES}

Corley, R. C. (1929). J. biol. Chem., 81, 81.

Guirdham, A., and Pettit, A. W. (1936). J. ment. Sci., 82, 119.

Herbert, F. K. (1938). Biochem. J., 32, 1,389.

Herbert, F. K., and Davison, G. (1938). Quart. J. Med., 7, 355.

$\mathbf{P}$ 
Hoskins, R. G., and Sleeper, F. H. (1933). Arch. Neurol. Psychiat., 30, 123.

Mann, S. A. (1925). J. ment. Sci., 71, 474.

Patterson, J. (1935). Biochem. J., 29, 1,398.

Quastel, J. H., and Wales, W. T. (1938). Lancet, 2, 301.

Radt, P. (1928). Biochem. Z., 198, 195.

Scott, L. D. (1933). J. Lab. clin. med., 18, 399.

Scott, L. D. (1935a). Biochem. J., 29, 1,012.

Scott, L. D. (1935b). Brit. J. exp. Path., 16, 489.

Stewart, C. P., Scarborough, H., and Davidson, J. N. (1937). Edinb. med. J., 44, 105.

Van Creveld, S. (1927). Klin. Wschr., 6, 697. 